\title{
Clinical interpretation of antineutrophil cytoplasmic antibodies: parvovirus B19 infection as a pitfall
}

\author{
J Hermann, U Demel, D Stünzner, E Daghofer, G Tilz, W Graninger
}

Ann Rheum Dis 2005;64:641-643. doi: 10.1136/ard.2004.024877

Background: While antibodies directed against proteinase 3 (PR3-ANCA) and myeloperoxidase (MPO-ANCA) have a high specificity for the diagnosis of systemic vasculitis, they may also be found as an epiphenomenon of acute viral infection.

Objective: To investigate whether positive ANCA test results may be a common feature of acute parvovirus B19 infection. Methods: Sera were analysed from 1242 patients from a rheumatology outpatient clinic for reactivity with parvovirus $B 19$ and EBV antibodies. They were tested for the presence of PR3-ANCA and MPO-ANCA, along with sera known to contain IgM antibodies to these viruses obtained from among 41366 samples submitted for virological screening.

Results: ANCA were found in 10\% $(5 / 50)$ of the sera positive for $\lg M$ antibodies to parvovirus and in $3 / 51$ sera containing IgM antibodies to EBV. Three of six patients with arthritis and concomitant parvovirus infection were found positive for PR3-ANCA and two were found positive for MPO-ANCA. All six patients tested negative for ANCA after six months of follow up.

Conclusions: PR3-ANCA and MPO-ANCA may occur transiently in patients with acute B19 infection or infectious mononucleosis, highlighting the importance of repeated antibody tests in oligosymptomatic clinical conditions in which systemic autoimmune disease is suspected.

$\mathrm{D}$ espite the low pretest likelihood, rheumatologists are sometimes tempted to use specific autoantibody tests to uncover the underlying disease. On the other hand, viral infections such as chronic hepatitis and cytomegalovirus infection may be associated with the production of a variety of autoantibodies. ${ }^{12}$

Detection of antineutrophilic cytoplasmic antibodies (ANCA) with high specificity to proteinase 3 (PR3-ANCA) and myeloperoxidase (MPO-ANCA) is now an important tool in the diagnosis of systemic vasculitis. ${ }^{3}$ Nevertheless, ANCA have also been described in patients with chronic hepatitis $\mathrm{C}$ infection, suggesting that viral infection may induce their production. ${ }^{4}$ Parvovirus B19 (B19) infection may predispose to the production of autoantibodies against Ro, Scl-70, and antiphospholipids. ${ }^{5}$ Molecular mimicry is the most popular hypothesis to explain autoantibody production in viral infection, and it proposes that viral antigens that share homologies with host antigens generate a cross reactive immune response. ${ }^{6}$ This can lead to diagnostic confusion in daily clinical practice.

After observing an index case presenting with polyarthritis, low grade fever, malaise, and positive PR3-ANCA and MPOANCA test results (see below) eventually diagnosed as an acute parvovirus B19 infection, we investigated whether positive ANCA test results might be a relatively common feature of acute B19 infection.

\section{PATIENTS AND METHODS}

A 24 year old woman (table 1, patient 1) presented in our outpatient clinic with polyarthritis, low grade fever, malaise, and a positive test result for PR3-ANCA and MPO-ANCA. Her erythrocyte sedimentation rate (ESR) was $10 \mathrm{~mm} / \mathrm{h}, \mathrm{C}$ reactive protein was normal, and she tested negative for rheumatoid factor and antinuclear antibodies (ANA). As examination of the upper respiratory tract, chest $x$ ray, and urine sediment were normal, and as specific antibodies to B19 were found by enzyme linked immunosorbent assay (ELISA) and immunoblot, B19 infection was considered and the patient was treated with a non-steroidal anti-inflammatory drug and low dose glucocorticoid. The clinical symptoms subsided three weeks later and PR3-ANCA and MPO-ANCA were negative after six months.

In a consecutive case series from 1998 to 2000, 1242 patients with suspected arthritis of peripheral joints attending our outpatient clinic were screened for serological evidence of acute B19 infection. Six female patients (mean age 34 years, range 18 to 44 ) presenting with mono-, oligo-, or polyarthritis, and a macular rash in two, were diagnosed as having acute B19 infection on the basis of specific IgM and IgG antibodies detected by ELISA and confirmed by immunoblot using the structural proteins VP-N, VP-C, and VB-1S, and the non-structural protein NS-1 of the B19 virus (Mikrogen GmbH, Munich, Germany). B19 viral nucleic acid was found in two of four patients tested by a nested polymerase chain reaction. $^{7}$

Blood was drawn from patients with B19 infection after informed consent had been obtained and was tested for the presence of PR3-ANCA and MPO-ANCA by specific ELISA (Orgentec Diagnostika, Mainz, Germany). The cut off level of the ELISA was $5 \mathrm{IU} / \mathrm{ml}$. Specificity of the ELISA for PR3ANCA and MPO-ANCA was reported to be $93-100 \%$ and the sensitivity $68 \%$ and $55 \%$, respectively. ${ }^{3}$ After six months and two years, all six patients were re-evaluated clinically. After the first six months serum samples were collected and retested for the presence of $\mathrm{B} 19$ IgM and IgG antibodies and PR3-ANCA and MPO-ANCA.

To further establish the frequency of ANCA in patients with acute viral infections, 41366 serum samples sent to the Institute of Hygiene between 2002 and 2003 were screened for IgM antibodies to B19 and Epstein-Barr virus (EBV). Forty four sera with IgM antibodies to B19, indicating acute B19 infection (11 male, 33 female; mean (SD) age, 42 (20) years), and 51 sera with IgM antibodies to EBV, indicating infectious mononucleosis (26 male, 25 female; age 23 (19) years) were subsequently tested for the presence of perinuclear (p)- or cytoplasmic (c)-ANCA by indirect

Abbreviations: ANCA, antineutrophil cytoplasmic antibodies; IIF, indirect immunofluorescence; MPO, myeloperoxidase; PR3, proteinase 3 
Table 1 Characteristics of six patients with acute parvovirus B19 infection at study entry (baseline)

\begin{tabular}{|c|c|c|c|c|c|c|c|c|c|c|}
\hline $\mathrm{Pt}$ & Sex & Age (y) & Joints involved & Rash & ESR $(\mathrm{mm} / \mathrm{h})$ & RF & ANA & $\begin{array}{l}\text { B } 19 \lg M / \lg G-A b \\
\text { (ELISA) }\end{array}$ & B $19 \lg M / \lg G-A b$ (IB) & B19 PCR \\
\hline 1 & $\mathrm{~F}$ & 24 & 6 & - & 10 & - & - & $+/+$ & $-/+$ & - \\
\hline 2 & $\mathrm{~F}$ & 39 & 7 & + & 29 & - & - & $+/+$ & $+/+$ & + \\
\hline 3 & $\mathrm{~F}$ & 36 & 4 & + & 14 & + & - & $+/+$ & $-/+$ & + \\
\hline 4 & $\mathrm{~F}$ & 28 & 10 & - & 17 & - & - & $+/+$ & $+/+$ & - \\
\hline 5 & $\mathrm{~F}$ & 32 & 4 & - & 10 & - & - & $+/+$ & $+/+$ & nd \\
\hline 6 & $\mathrm{~F}$ & 44 & 1 & - & 11 & - & - & $+/+$ & $-1+$ & nd \\
\hline
\end{tabular}

ANA, antinuclear antibodies; B19 lgM/lgG-Ab, parvovirus B19 lgM and lgG antibodies; ELISA, enzyme linked immunosorbent assay; ESR, erythrocyte sedimentation rate; F, female; IB, immunoblot; nd, not done; PCR, polymerase chain reaction; Pt, patient; RF, rheumatoid factor; $y$, years; +, positive; -, negative.

immunofluorescence (IIF) on ethanol, formalin, and methanol fixed granulocytes (Scabos Diagnostics, Vienna, Austria) and for PR3-ANCA and MPO-ANCA by ELISA (Orgentec Diagnostika, Mainz, Germany).

Descriptive statistics were carried out using the software package StatView version 5.0.

\section{RESULTS}

Outpatients with B 19 infection and detection of ANCA Of the six patients diagnosed with acute B19 infection, two presented with oligoarthritis, three with polyarthritis, one with monoarthritis, and two had a macular rash (table 1). Five patients with B19 infection reported morning stiffness lasting between 30 and 210 minutes. The ESR was raised in five patients and $C$ reactive protein levels were high in three patients. A positive rheumatoid factor at low titre was found in two patients. Antinuclear antibodies were negative in all patients. One patient tested positive for PR3-ANCA and two for PR3-ANCA and MPO-ANCA (table 2). In three patients with B19 infection, neither PR3-ANCA nor MPO-ANCA was detectable either at study entry or after six months of follow up. After six months, peripheral joint disease and the macular rash-when present-had subsided in and all patients showed B19 seroconversion, demonstrating adequate immune response to the virus (table 2). No clinical signs or symptoms of systemic vasculitis were found in those patients positive for PR3-ANCA or MPO-ANCA, even after a follow up of two years' duration. Importantly, all patients with raised PR3-ANCA and/or MPO-ANCA at study entry tested negative after six months of follow up. Raised ESR and $\mathrm{C}$ reactive protein levels normalised after six months.

\section{Serum samples from patients with serological} constellation of acute B 19 or EBV infection

Two of 44 serum samples (5\%) positive for B19 IgM antibodies tested positive for p-ANCA in the IIF at a titre of 1:320. One of the two positive samples also tested positive for MPO-ANCA by ELISA at a level of $49.5 \mathrm{U} / \mathrm{ml}$. Of the 51 EBV
IgM antibody positive sera, one showed an IIF pattern of pANCA at a titre of 1:320 and two a titre of 1:40, but neither of them was positive for MPO-ANCA or PR3-ANCA by ELISA. Conversely, no serum sample negative for ANCA by IIF tested positive for PR3-ANCA or MPO-ANCA.

\section{DISCUSSION}

Patients presenting with arthralgia or arthritis are often a major challenge for rheumatologists because diseases as different as viral infection or systemic vasculitis may finally evolve from such a monosymptomatic clinical condition. Parvovirus infection associated with self limiting non-erosive arthritis occurs in up to $12 \%$ of adults attending an early arthritis clinic. ${ }^{8}$ Conversely, Wegener's granulomatosis may also present with arthralgia, and non-erosive arthritis can be an early symptom in more than $25 \%$ of patients. ${ }^{9}$ Hence, reliable antibody tests to distinguish Wegener's granulomatosis from viral infection are needed.

In our clinical series of patients with arthritis and acute B19 infection, a commonly used ELISA detected PR3-ANCA and MPO-ANCA in three of six patients in the early phases of infection. Six months later, when clinical symptoms had subsided and seroconversion had indicated resolution of acute B19 infection, PR3-ANCA and MPO-ANCA were no longer detectable. When we subsequently tested 44 sera from individuals with acute B19 infection by IIF and ELISA we found ANCA in two of them, which reinforces the hypothesis that false positive ANCA may occur during acute parvovirus infection. An analogous approach with EBV antibodies yielded similar findings. The trivial explanation for our observation, such as a non-specific reaction of the ELISA test system, cannot be fully excluded as we did not have enough sera left for IIF or immunoblotting in the clinical series of arthritis patients. However, the occurrence of ANCA found by IIF in 5\% of individuals with acute B19 infection suggests that there is a pathophysiological context for viral infection and the development of ANCA. This is supported theoretically by the following: the presence of B19 viral DNA

Table 2 ELISA test results for the detection of PR3-ANCA and MPO-ANCA of six patients with arthritis and acute parvovirus B19 infection at baseline and after a follow up of six months

\begin{tabular}{|c|c|c|c|c|c|}
\hline \multirow[b]{2}{*}{ Pt } & \multicolumn{2}{|l|}{ Baseline } & \multicolumn{3}{|l|}{ Six months } \\
\hline & $\begin{array}{l}\text { PR3-ANCA } \\
\text { (IU/ml) }\end{array}$ & $\begin{array}{l}\text { MPO-ANCA } \\
\text { (IU/ml) }\end{array}$ & PR3-ANCA (IU/ml) & MPO-ANCA (IU/ml) & B $19 \lg M / \lg G$ Ab \\
\hline 1 & 28.1 & 11.6 & - & - & $-/+$ \\
\hline 2 & 27.0 & - & - & - & $-/+$ \\
\hline 3 & 79.0 & 15.1 & - & - & $-/+$ \\
\hline 4 & - & - & - & - & $-/+$ \\
\hline 5 & - & - & - & - & $-/+$ \\
\hline 6 & - & - & - & - & $-/+$ \\
\hline \multicolumn{6}{|c|}{$\begin{array}{l}\text { Ab, antibodies; ANCA, antineutrophil cytoplasmic antibodies; } B 19 \lg M / \lg G-A b \text {, parvovirus B19 } \lg M-\text { and } \lg G \\
\text { antibodies; ELISA, enzyme linked immunosorbent assay; } M P O \text {, myeloperoxidase; PR3, proteinase 3; Pt, patient; - } \\
\text { negative; -/+, IgM antibody negative and } \lg G \text { antibody positive. }\end{array}$} \\
\hline
\end{tabular}


in tissues from patients with Wegener's granulomatosis ${ }^{10}$; the fact that B19 can inoculate and thereby activate endothelial cells $^{11}$; and the fact that PR3 is expressed on activated endothelial cells and neutrophils. ${ }^{12}$ In support of our findings, a Taiwanese group also reported four cases of B19 infection with a positive p-ANCA test, and they too detected both MPO-ANCA and PR3-ANCA in two of them. ${ }^{13}$

\section{Conclusions}

ANCA were found in 5\% of patients with clinically and serologically diagnosed B19 infection and in a random sample of sera of patients with acute B19 and EBV infection by a routine ELISA and in two cases by IIF. ANCA were no longer detectable after acute B19 infection had subsided, suggesting an association with the viral infection. We therefore propose that in clinical situations with a low pretest probability, even those autoantibody tests known to be highly specific for autoimmune diseases should be repeated after a certain interval if these test results are essential for the diagnosis.

\section{Authors' affiliations \\ J Hermann, U Demel, G Tilz, W Graninger, Department of Internal Medicine, Medical University, Graz, Austria \\ D Stünzner, E Daghofer, Institute of Hygiene, Medical University, Graz}

Correspondence to: Dr Josef Hermann, Medical University, Graz, Department of Internal Medicine, Division of Rheumatology, Auenbruggerplatz 15, A-8036 Graz, Austria; josef.hermann@ meduni-graz.at

Accepted 22 August 2004

Published Online First 14 October 2004

\section{REFERENCES}

1 Gregorio GV, Jones H, Choudhuri K, Vegnente A, Bortolotti F, MieliVergani $G$, et al. Autoantibody prevalence in chronic hepatitis $B$ virus infection: effect on interferon alfa. Hepatology 1996;24:520-3.

2 Varani S, Muratori L, De Ruvo N, Vivarelli M, Lazzarotto T, Gabrielli L, et al. Autoantibody appearance in cytomegalovirus-infected liver transplant recipients: correlation with antigenemia. J Med Virol 2002;66:56-62.

3 Csernok E, Ahlquist D, Ullrich S, Gross WL. A critical evaluation of commercial immunoassays for antineutrophil cytoplasmic antibodies directed against proteinase 3 and myeloperoxidase in Wegener's granulomatosis and microscopic polyangiitis. Rheumatology (Oxford) 2002;41:1313-17.

4 Ohira H, Tojo J, Shinzawa J, Suzuki T, Miyata M, Nishimaki T, et al. Antineutrophil cytoplasmic antibody in patients with antinuclear antibodypositive chronic hepatitis C. Fukushima J Med Sci 1998;44:83-92.

5 Von Landenberg P, Lehmann HW, Knoll A, Dorsch S, Modrow S. Antiphospholipid antibodies in pediatric and adult patients with rheumatic disease are associated with parvovirus B19 infection. Arthritis Rheum 2003;48:1939-47.

6 Barnett LA, Fujinami RS. Molecular mimicry: a mechanism for autoimmune injury. FASEB J 1992;6:840-4.

7 Gassinotti P, Weitz M, Siegl G. Human parvovirus B19 infections: routine diagnosis by a new nested polymerase chain reaction assay. J Med Virol 1993;40:228-34

8 White DG, Mortimer PP, Blake DR, Woolf AD, Cohen BJ, Bacon PA. Human parvovirus arthropathy. Lancet, 1985;i, 419-21.

9 Noritake DT, Weiner SR, Bassett LW, Paulus HE, Weisbart R. Rheumatic manifestations of Wegener's granulomatosis. J Rheumatol 1987;14:949-51

10 Finkel TH, Torok TJ, Ferguson PJ, Durigon EL, Zaki SR, Leung DY, et al. Chronic parvovirus B19 infection and systemic necrotising vasculitis: opportunistic infection or aetiological agent? [see comments]. Lancet 1994;343:1255-8.

11 Magro CM, Nuovo G, Ferri C, Crowson AN, Giuggioli D, Sebastiani M. Parvoviral infection of endothelial cells and stromal fibroblasts: a possible pathogenetic role in scleroderma. J Cutan Pathol 2004;31:43-50.

12 Mayet WJ, Schwarting A, Meyer zum Buschenfelde KH. Cytotoxic effects of antibodies to proteinase 3 (c-ANCA) on human endothelial cells. Clin Exp Immunol 1994;97:458-65.

13 Chou TN, Hsu TC, Chen RM, Lin LI, Tsay GJ. Parvovirus B19 infection associated with the production of anti-neutrophil cytoplasmic antibody (ANCA) and anticardiolipin antibody (aCL). Lupus 2000;9:551-4. 